\title{
Prevent and predict
}

\author{
As the COVID-19 outbreak continues, the next pandemic could be prevented by ending the wildlife trade and \\ reinvesting in the monitoring of potential zoonoses.
}

$\mathrm{T}$ he COVID-19 epidemic continues to spread from its origin in Wuhan, China. We do not yet know whether it will become a global pandemic, and epidemiologists are scrutinizing the key numbers that will determine this. Whatever the eventual outcome, it has already claimed more lives than the 2002-2003 SARS outbreak, even if the mortality rate is lower. Both SARS-CoV-2, the virus responsible for COVID-19, and the earlier SARS-CoV have zoonotic origins, as do the viruses behind many other recent epidemics. This means there are two clear lessons for reducing the chances of a similar event in the future: prevention, by stopping the harmful wildlife trade; and prediction, by continuing to fund zoonoses monitoring programmes.

The original host for SARS-CoV-2 was probably bats ${ }^{1}$, but an intermediate host would have been involved in the transition to humans. At the time of writing, there is considerable speculation that this was pangolins. If confirmed, the outbreak would follow a similar pattern to the 2002 SARS virus, which transitioned from bats to humans via civet cats involved in the wildlife trade ${ }^{2}$. Trade in pangolins in China is illegal, but continues nevertheless because their meat and scales are highly valued. Although pangolins were not listed on the inventory of the Wuhan wildlife market thought to be the origin of the outbreak, it is possible that illegal pangolin trade was occurring there. Regardless of the actual species involved, COVID-19 highlights the urgent case for permanent closure of the legal wildlife trade, as well as attempts to prevent its illegal counterpart.

A temporary ban is already in place in China, as occurred after the 2003 outbreak. However, a temporary ban has little effect on the current outbreak, which is already circulating in humans, and its effect on future outbreaks disappears as soon as it is lifted. Scientists called for a permanent ban last time, and are calling for it again. But there are also concerns that top-down control over the trade is not enough ${ }^{3}$.
In addition to regulatory control, each stage of the trade, from supply through to demand, needs to be tackled with differing but interdisciplinary measures, such as alternative incentives for suppliers and behavioural nudges to reduce demand ${ }^{4}$. Interdisciplinary approaches, incorporating the social sciences, are vital to avoid casting "worldviews and social responses of local people... as 'risky behaviour', ignorance or superstition, and as generating 'unnecessary' resistance to control efforts" ${ }^{5}$. It is important to note that the problem is not restricted to China, with similar markets present in other Asian countries and demand being driven from all over the world. However, the size of China means that changes there would have a far greater effect than similar actions anywhere else.

There is a danger that the message about zoonoses can become twisted so that wildlife is blamed, as opposed to the human exploitation of wildlife, which is the actual problem. Bats are a reservoir for many diseases and can therefore get a bad press, so it is important to keep emphasizing that these diseases would remain safely in bats were it not for specific human disturbances, and that the ecosystem services provided by bats greatly outweigh any risk they pose. Likewise, the endangered species that are often intermediate hosts are only so because they have been brought into the artificial conditions of wildlife markets, and leaving them alone and protecting their habitat is the best course of action. If this messaging can be achieved (and again, in a culturally sensitive manner, acknowledging the drivers of the trade and instituting appropriate incentives and disincentives), then an end to the wildlife trade would be an enormous gain for conservation as well as disease prevention, as the trade is one of the strongest threats for many species.

Even if the wildlife trade is ended, it is impossible to prevent all potential routes for zoonotic transfer. It is therefore important that we monitor the diseases circulating in species and locations of particular concern.
In 2017, we published a Feature focusing on the PREDICT project, which aimed to provide just such monitoring at a global scale. However, in late 2019, just as COVID-19 was starting to emerge, albeit as yet undetected, PREDICT was closed down when its funding from the United States Agency for International Development was not renewed. While it is true that funding cycles come to an end and tough decisions must be made, the loss of this project could not have been more untimely. PREDICT had collected 140,000 samples from animals, identified 1,000 new viruses, and trained 5,000 people across Asia and Africa. The COVID-19 outbreak demonstrates the importance of finding a way for this or similar work to continue.

While scientists, clinicians and governments rightly focus on containing COVID-19, they should also take the opportunity to prevent finding ourselves in a similar situation just a few years down the line. With China scheduled to host the key Convention on Biological Diversity conference to set the post-2020 biodiversity agenda, it is hoped that the double win for disease prevention and conservation of permanently closing the wildlife trade will be seized. This is an opportunity for China to demonstrate that it is serious about both tackling COVID-19 and its sustainability commitments. And with vast sums of money being spent globally fighting COVID-19, as well as the resulting economic losses, it is hoped that the much more modest sums required for monitoring zoonoses will be seen by governments and funders worldwide for the great deal that they are.

Published online: 20 February 2020

https://doi.org/10.1038/s41559-020-1150-5

References

1. Zhou, P. et al. Nature https://doi.org/10.1038/s41586-020-2012-7 (2020).

2. Hu, B. et al. PLOS Pathog. 13, e1006698 (2017).

3. Blair, M. E. et al. BioScience 67, 995-1003 (2017).

4. Wallen, K. E. \& Daut, E. Nat. Conserv. 26, 55-75 (2018).

5. MacGregor, H. \& Waldman, L. Phil. Trans. R. Soc. B 372, 20160170 (2017). 